\title{
Combining faecal immunochemical testing with blood test results to identify patients with symptoms at risk of colorectal cancer: a consecutive cohort of 16,604 patients tested in primary care
}

Diana R Withrow ${ }^{1}$, Brian Shine ${ }^{2}$, Jason Oke ${ }^{1}$, Andres Tamm³ ${ }^{3}$ Tim James², Eva Morris ${ }^{3}$, Jim Davies $^{4}$, Steve Harris ${ }^{5}$, James E East ${ }^{6}$, Brian D Nicholson ${ }^{1^{*}}$

${ }^{1}$ Nuffield Department of Primary Care Health Sciences, Medical Sciences Division, University of Oxford, Radcliffe Observatory Quarter, Oxford, OX2 6GG, United Kingdom

${ }^{2}$ Department of Clinical Biochemistry, John Radcliffe Hospital, Oxford University Hospitals NHS Foundation, Oxford, United Kingdom

${ }^{3}$ Nuffield Department of Population Health, Big Data Institute, University of Oxford, Oxford, United Kingdom

${ }^{4}$ Department of Computer Science, Big Data Institute, University of Oxford, Oxford, United Kingdom

${ }^{5}$ Oxford BRC Informatics Theme, Big Data Institute, University of Oxford, Oxford, United Kingdom

${ }^{6}$ Translational Gastroenterology Unit, John Radcliffe Hospital, University of Oxford, Oxford, United Kingdom

* Corresponding author

Word count: 3453 
medRxiv preprint doi: https://doi.org/10.1101/2021.10.22.21263919; this version posted October 26, 2021. The copyright holder for this preprint (which was not certified by peer review) is the author/funder, who has granted medRxiv a license to display the preprint in perpetuity.

All rights reserved. No reuse allowed without permission.

\section{Structured abstract:}

Objective: Faecal immunochemical tests (FITs) are used to triage primary care patients with low risk colorectal cancer symptoms for referral to colonoscopy. The aim of this study was to determine whether combining FIT with routine blood test results could improve the performance of FIT in the primary care setting.

Design: Results of all consecutive FITs requested by primary care providers between March 2017 and December 2020 were retrieved from the Oxford University Hospitals NHS Foundation Trust. Demographic factors (age, sex), reason for referral, and results of blood tests within 90 days were also retrieved. Patients were followed up for incident colorectal cancer in linked hospital records. The sensitivity, specificity, positive and negative predictive values of FIT alone, FIT paired with blood test results, and several multivariable FIT models, were compared.

Results: Among 16,604 eligible patients, 139 colorectal cancers were diagnosed ( $0.8 \%)$. Sensitivity and specificity of FIT alone at a threshold of $10 \mu \mathrm{g} \mathrm{Hb} / \mathrm{g}$ were $92.1 \%$ and $91.5 \%$ respectively. Compared to FIT alone, blood test results did not improve the performance of FIT. Pairing blood test abnormalities with FIT reduced the number of abnormal results needed to detect one cancer but increased the number of cancers missed. Multivariable models retaining FIT, sex, and mean cell volume performed similarly to FIT alone.

Conclusion: FIT is a highly sensitive tool for identifying higher risk individuals presenting to primary care with lower risk symptoms. Combining blood test results with FIT does not appear to lead to better discrimination for colorectal cancer than using FIT alone.

\section{Author contributions}

Diana R Withrow: conceptualisation, data curation, formal analysis, investigation, methodology, visualisation, writing - original draft, and writing - review \& editing

Brian Shine: data curation, methodology, resources, writing - review \& editing

Jason Oke: conceptualisation, data curation, formal analysis, funding acquisition, investigation, methodology, supervision, and writing - review \& editing

Andres Tamm: formal analysis, methodology, visualisation, writing - review \& editing

Tim James: data curation, methodology, project administration, writing - review \& editing

Eva Morris: supervision, writing - review \& editing

Jim Davies: data curation, writing - review \& editing

Steve Harris: data curation, writing - review \& editing

James East: conceptualisation, funding acquisition, supervision, writing - review \& editing

Brian D Nicholson: conceptualisation, formal analysis, funding acquisition, investigation, methodology, project administration, supervision, writing - original draft, and writing - review \& editing

\section{Conflicts of interest}

The authors have no conflicts of interest to declare.

\section{Role of the funding source}


medRxiv preprint doi: https://doi.org/10.1101/2021.10.22.21263919; this version posted October 26, 2021. The copyright holder for this preprint (which was not certified by peer review) is the author/funder, who has granted medRxiv a license to display the preprint in perpetuity.

All rights reserved. No reuse allowed without permission.

The work was supported by Cancer Research UK (CR-UK) grant number C5255/A18085 through the Cancer Research UK Oxford Centre and Oxford Centre for Early Cancer Detection (OxCODE). James East and Jim Davies are funded by the National Institute for Health Research (NIHR) Oxford Biomedical Research Centre. BDN is an NIHR Academic Clinical Lecturer and is supported by the NIHR Oxford Medtech and In-Vitro Diagnostics Cooperative. JO is part funded by the NIHR Oxford Biomedical Research Centre, Oxford University Hospitals NHS Foundation Trust. None of the funding sources had any involvement in the conduct of study or preparation of this manuscript.

\section{Ethics committee approval}

This study was conducted as a service evaluation with registration, review and approval process within the OUH Datix governance structure (Service evaluation registration identifier: CSS-BIO-3-4730). As service evaluation, this work is not subject to the Department of Health's UK Policy Framework for Health and Social Care Research (2017). The Sponsorship and Ethics Lead within the Research Governance, Ethics and Assurance Team in the Research Support Office at the University of Oxford has confirmed that it requires neither sponsorship nor research ethics review.

\section{Acknowledgements}

This research uses data provided by patients and collected by the NHS as part of their care and support. We appreciate feedback from Patrick McGuire. The views expressed are those of the authors and not necessarily those of the National Health Service, the NIHR or the Department of Health. 


\section{Introduction}

Diagnosing colorectal cancer in patients who present to primary care can be challenging because many of the symptoms of colorectal cancer are shared with other, less serious causes. Colonoscopy is the definitive test to diagnose colorectal cancer, but referring all patients with symptoms of possible colorectal cancer for colonoscopy would cause significant strain on health care resources and present unnecessary risks to patients ${ }^{1}$. In 2017, the faecal immunochemical test (FIT) was recommended by the National Institute for Health and Care Excellence (NICE) as a triage test for patients presenting to primary care with low risk symptoms of possible colorectal cancer ${ }^{2}$. The evidence underpinning that recommendation was drawn primarily from higher risk populations and there was limited evidence about how it would perform in primary care ${ }^{3-5}$.

There has been a rapid increase in publications about FIT use in symptomatic patients over the last five years ${ }^{367}$. FIT has consistently been shown to have high sensitivity and specificity for colorectal cancer at a threshold of $10 \mu \mathrm{g} \mathrm{Hb} / \mathrm{g}$ faeces or lower, in primary and secondary care ${ }^{7-9}$. Despite a high negative predictive value, nearly one in ten colorectal cancers will be missed using FIT alone to select who should be referred for investigation ${ }^{10}$. Developing strategies to identify symptomatic people with FIT negative colorectal cancer has become an urgent priority due to the increased use of FIT to defer or decline colorectal investigation during the COVID-19 pandemic ${ }^{11}$. Furthermore, as the number of colorectal cancer presentations is expected to increase, and health care resources continue to be strained by ongoing effects of the pandemic, efforts to reduce unnecessary referrals by increasing specificity would be especially worthwhile ${ }^{11}$.

Clinical prediction models are one strategy to achieve these aims. However, the faecal haemoglobin age and sex test (FAST) score did not improve utility over FIT alone ${ }^{12}$. FIT has also been shown to outperform multivariable models including age, sex and symptoms prompting urgent cancer referral ${ }^{13}$. Combining commonly used blood tests with FIT could further optimise the triage of symptomatic patients in primary care for colorectal cancer investigation ${ }^{1415}$.

Using the largest existing UK cohort of symptomatic patients tested with FIT in primary care, the aim of this study was to assess whether complementing FIT with blood test values could improve the predictive performance of $\mathrm{FIT}^{16}$.

\section{Methods}

\section{Study design}

\section{Population/Setting}

Data were retrieved from Oxford University Hospitals NHS Foundation Trust (OUH). OUH serves all primary care clinicians in the county of Oxfordshire, UK, with a population of approximately 660,000. Based at the John Radcliffe Hospital, the Clinical Biochemistry Laboratory performs over 8 million tests a year. This study was registered as a service evaluation on the OUH Datix register (CSS-BIO-3 4730).

FITS

All consecutive FIT results (measured in $\mu \mathrm{g} \mathrm{Hb} / \mathrm{g}$ faeces) between March 2017 and December $21^{\text {st }} 2020$ were retrieved retrospectively from the OUH Clinical Biochemistry Laboratory Information Management System. The end date for eligible FITs was determined to allow a minimum of 6 months follow-up for all participants. 
medRxiv preprint doi: https://doi.org/10.1101/2021.10.22.21263919; this version posted October 26, 2021. The copyright holder for this preprint (which was not certified by peer review) is the author/funder, who has granted medRxiv a license to display the preprint in perpetuity.

All rights reserved. No reuse allowed without permission.

After restricting to FITs requested by primary care clinicians and the first FIT in any given individual, FITs were retained for inclusion in this analysis if the five most common "core" blood tests (haemoglobin, platelets, white cell count, $\mathrm{MCH}$ and MCV) were available, patients were aged 18 or older, had known sex, and had non-missing FIT results (Figure 1).

Faecal specimens were collected into standard pots by patients in primary care and referred to the central laboratory where sampling was undertaken using the Extel Hemo-Auto MC device. Prepared samples were analysed for FIT using the HM-JACKarc analyser (Hitachi Chemical Diagnostics Systems Co., Ltd, Tokyo, Japan and distributed in the UK by Alpha Labs Ltd, Eastleigh, Hants) a method recommended for use by $\mathrm{NICE}^{2}$. The method had a calibration range of 7-400 $\mu \mathrm{g} \mathrm{Hb} / \mathrm{g}$ faeces. Immunoassay reproducibility assessed across 12 months had a coefficient of variation (CV) of between 4.4 and $8.8 \%$. The overall imprecision of the process including sampling variation was between 7.0 and $13.5 \mathrm{CV} \%{ }^{17}$. FIT samples were assayed and recorded prior to and independent of the any subsequent pathology findings.

\section{Additional variables}

Age, sex, clinical indication, and results of contemporaneous blood tests were retrieved for each patient. To extract the clinical indication, free text fields for the reason for referral were searched for common indications (abdominal pain, bloating, blood in stool, change in bowel habit, constipation, diarrhoea, family history of cancer, fatigue, melaena, rectal pain, and weight loss) using numerous permutations of spelling and phrasing. A $20 \%$ sample was reviewed to ensure validity of free text coding.

Blood test results reported less than 60 days prior to or 30 days post FIT were retrieved. The most routinely used blood tests and those with a hypothesized relationship with colorectal cancer risk were selected for analysis (haemoglobin, platelets, white cell count, mean cell haemoglobin $(\mathrm{MCH})$, mean cell volume (MCV); serum ferritin and c-reactive protein [CRP]) 18. The same analytical methods for the blood tests were used throughout the study period: full blood count, including haemoglobin, platelets, white cell count, $\mathrm{MCH}$ and $\mathrm{MCV}$ were analysed using a Sysmex XN analyser (Sysmex UK Ltd, Milton Keynes, UK); ferritin using an Abbott Architect i2000 and CRP using the Abbott Architect c16000 (both Abbott Diagnostics UK, Maidenhead, UK).

\section{Outcomes}

A composite reference standard was used as not all patients tested with FIT in primary care are referred for definitive testing. A reliance on definitive testing alone would lead to verification bias for FIT positive patients. The composite reference standard incorporated the review of multiple linked databases (hospital clinical records, pathology results, and endoscopy and radiology reports) for evidence of a new colorectal cancer diagnosis within the follow-up period, which was 6 months in the primary analysis. Database review was independent of FIT value.

\section{Patient \& Public Involvement}

No patients were directly involved in designing the research question or in conducting the research. A patient advocate provided feedback on interpretation of the results and key messages. Our findings will be disseminated to patients and the public through the NIHR BRC, Nuffield Department of Primary Care Health Sciences, Oxford Cancer, and OxCODE. 


\section{Statistical Analysis}

Three approaches were investigated to optimise FIT.

1. FIT alone - dichotomous FIT at a cut-off of greater than or equal to 2 or $10 \mu \mathrm{g} \mathrm{Hb} / \mathrm{g}$ faeces;

2. FIT-Blood test pairs - dichotomous FIT and dichotomous blood test result;

A test was considered positive if patients fell above the cut-off value for FIT (2 or $10 \mu \mathrm{g} \mathrm{Hb} / \mathrm{g}$ faeces) and had an abnormal blood test result. The threshold for abnormal blood tests were pre-specified based on standard clinical practice ${ }^{19}$.

3. Multivariable FIT - modeling including FIT, blood tests, age and sex.

Logistic regression was used to generate predicted probabilities of colorectal cancer. Backward stepwise selection was used to select covariates. Because serum ferritin and CRP were only available for a subset of cases, stepwise selection was conducted on an imputed dataset with 10 replicates using predictive mean matching. In models where CRP or serum ferritin were retained, coefficients for each variable in the imputed and complete case datasets were compared and if similar, the model results from the complete case dataset were reported. The three modeling approaches are defined below.

Model A: FIT, age, and blood test results (continuous); sex (dichotomous).

Model B: FIT and blood test results (dichotomous); age (categorical); and sex (dichotomous)

Model C: FIT (spline), age (continuous), sex and blood tests (dichotomized).

The restricted cubic spline function for FIT was specified to have knots at 2, 10, 50 and 100 $\mu \mathrm{g} \mathrm{Hb} / \mathrm{g}$ faeces. Four knots were selected to yield a model with at least 20 events per variable, to minimize optimism bias ${ }^{20}$. Ninety-five percent confidence intervals were estimated using the Wilson Score method ${ }^{21}$. The positive predictive value (PPV) and negative predictive value (NPV) were additionally expressed as the number of positive FITs to detect one cancer (number needed to scope) and the cancer miss rate per 10,000 negative tests. To permit a comparison of model performance, the probability cut-off to determine a positive result was selected to match the sensitivity of the FIT alone at a cut-off of $10 \mu \mathrm{g} \mathrm{Hb} / \mathrm{g}$ faeces.

\section{Sensitivity \& Subgroup Analyses}

The FIT alone approach was applied to subgroups defined by FIT date (prior to or during the COVID-19 pandemic), age-group ( $<40,>50,>60,>70,>80)$, sex, blood test results and clinical indication. Each of the approaches 1, 2, and 3 outlined above were replicated with 12 months of follow-up.

\section{Results}

Descriptive

A total of 16,604 of 18,656 available FITs (89\%) were included in the study. Included patients were representative of the overall sample (Table 1). Study subjects had a median 
age of 61 and were $58 \%$ female. One-hundred and thirty-nine (139) cancers were diagnosed within six months of the FIT test $(0.8 \%)$. Patients who were diagnosed with cancer were older (median age 72) and more likely to be male (60\%), to have a FIT $\geq 10 \mu \mathrm{g} \mathrm{Hb} / \mathrm{g}$ faeces and/or to have abnormal blood tests (Table 1, Figure 2, Supplementary Table 1).

Ninety percent of patients had at least one reported clinical indication, most commonly change in bowel habit (40\%) then anaemia (26\%) and abdominal pain (18\%, Table 1). The most common clinical indications in people with cancer were anaemia (35\%), change in bowel habit (32\%), blood in stool (16\%) and abdominal pain (17\%).

Low haemoglobin was the most common abnormal blood test result ( $31 \%$ of all patients, $52 \%$ of those with a subsequent cancer diagnosis, Table 1) followed by low $\mathrm{MCH}$ ( $16 \%$ and $34 \%$ respectively).

\section{1) FIT alone}

At a FIT threshold of $2 \mu \mathrm{g} \mathrm{Hb} / \mathrm{g}$ faeces sensitivity was $96.4 \%$ (95\% Cl: 91.9-98.5), specificity 83.5\% (95\% Cl: 82.9-84.1), PPV 4.7\% (95\% Cl: 4.0-5.5), and NPV 100\% (95\% Cl: 99.9-100) (Table 2, Supplementary Table 2). One cancer was detected for every twenty-one positive FITs, and the cancer miss rate was 4 cancers per 10,000 negative tests (Table 2).

At $10 \mu \mathrm{g} \mathrm{Hb} / \mathrm{g}$ faeces, sensitivity was $92.1 \%$ (95\% Cl: 86.4-95.5), specificity $91.5 \%$ (95\% Cl: 91.1-91.9), PPV 8.4\% (95\%Cl: 7.1-9.9) and NPV 99.9\% (95\% Cl: 99.9-100) (Table 2, Supplementary Table 2). One cancer was detected for every twelve positive FITs, and a miss rate of 7 cancers per 10,000 negative tests (Table 2).

\section{2) FIT-Blood Test Pairs}

Sensitivity ranged from $3.3 \%$ (FIT $\geq 2$ or $10 \mu \mathrm{g} \mathrm{Hb} / \mathrm{g}$ faeces and raised CRP) to $56.8 \%$ (FIT $\geq 2$ $\mu \mathrm{g} \mathrm{Hb} / \mathrm{g}$ faeces and low serum ferritin) for pairings of FIT and blood tests. Specificity was higher for almost all pairings compared to a FIT-alone approach leading to fewer positives being needed to detect one cancer. However, the cancer miss rate per 10,000 tests increased 14-fold compared to a FIT alone approach (Table 2).

\section{3) Multivariable FIT}

A) Model A (with continuous FIT): sex and continuous variables for age, serum ferritin, platelets and CRP were retained. Specificity was 45.9\% (95\% Cl 44.7-47.1), compared to $90.0 \%$ for FIT alone (in the subset with serum ferritin and CRP), leading to one cancer in every 57 positive tests compared to one in 12 in the FIT-only approach (Table 3, Supplementary Table 2).

B) Model B (dichotomous FIT, blood tests): FIT, sex and low MCV were retained. Specificity was $90.1 \%$ (95\% Cl: 89.6-90.5), similar to FIT alone at FIT $\geq 10 \mu \mathrm{g} \mathrm{Hb} / \mathrm{g}$ faeces, leading to 14 positive tests to detect one cancer.

C) Model C (FIT spline): FIT, sex, and low MCV were retained. Specificity was $91.5 \%$ (95\% Cl: 91.1-91.9) with one cancer detected for every 12 positive FITs.

In summary, Models B and C performed similarly to FIT alone but no approach that integrated blood test results improved the overall performance of FIT. Odds ratios for the predictors and the log likelihood and Area Under the Curve for each model are provided in Supplementary Table 3. A plot of apparent calibration did not reveal any causes for concern. 
medRxiv preprint doi: https://doi.org/10.1101/2021.10.22.21263919; this version posted October 26, 2021. The copyright holder for this preprint (which was not certified by peer review) is the author/funder, who has granted medRxiv a license to display the preprint in perpetuity.

All rights reserved. No reuse allowed without permission.

The age-specific probabilities of colorectal cancer by sex and FIT score based on Model C are illustrated in Figure 3. For males and females, the probability of colorectal cancer reached $3 \%$ (the cut-off specified to prompt urgent investigation by NICE ${ }^{22}$ ) at FIT values of 17 and 25 respectively. There were no significant differences by age since age was not a significant predictor of cancer risk after accounting for FIT (Supplementary Table 3).

\section{FIT-negative cancers}

The characteristics of the 11 patients with false negative tests at a FIT threshold of $10 \mu \mathrm{g}$ $\mathrm{Hb} / \mathrm{g}$ faeces are provided in Table 3. Ten had at least one GP-reported clinical indication with the most common being change in bowel habit $(n=6)$. Eight of the 11 had at least one abnormal blood test with the most common being raised CRP ( 5 of 10 with known values). Median days from FIT to cancer diagnosis was 27 days among false negatives (interquartile range 21 to 55$)$ compared to $34(21,64)$ among persons diagnosed with cancer overall.

\section{Subgroup and sensitivity analyses}

Patient demographics, clinical indication, prevalence of abnormal blood tests, FIT score, and performance of FIT were largely consistent prior to and during the COVID-19 pandemic (Supplementary Tables 4, 5). The median age of persons undergoing FIT was older during COVID (64 vs. 59 years) but the interquartile range was similar (51 to 76 vs. 51 to 74). There were no significant differences in sensitivity, specificity, PPV or NPV of FIT.

PPV was higher among males than females, but the confidence intervals for the two sexes overlapped at a threshold of $10 \mu \mathrm{g} \mathrm{Hb} / \mathrm{g}$ faeces. At $2 \mu \mathrm{g} \mathrm{Hb} / \mathrm{g}$ faeces, PPV and NPV decreased with increasing age. At $10 \mu \mathrm{g} \mathrm{Hb} / \mathrm{g}$ faeces, PPV and NPV were largely consistent by age group (Supplementary Table 6 ).

There was no evidence that the PPV of FIT was significantly higher within subgroups defined by clinical indication or blood test other than MCV (Supplementary Table 6).

Results did not meaningfully change when the follow-up period was extended to 12 months (Supplementary Tables 7 and 8).

\section{Discussion}

\section{Summary of findings}

In this large cohort of symptomatic patients tested with FIT in primary care, neither age, nor blood test results remained strong enough predictors of colorectal cancer to improve on the performance of FIT. While the number of false positives could be reduced by taking into account blood tests, the large associated increase in false negatives outweighed the benefit. In addition, there was no evidence to suggest that using clinical indication as a rule-out or rule-in factor would improve the efficiency of FIT triage.

It may seem counter-intuitive that blood tests known to be associated with colorectal cancer did not improve the performance of FIT. When using FIT for triage in primary care, sensitivity is valued over specificity (i.e., reducing false negatives is more valued than reducing false positives). Accordingly, for a model to outperform FIT, additional predictors must enhance the model's ability to distinguish those with and without cancer specifically within the population who have a FIT value around the FIT threshold. Most people tested will have a negative FIT and many of these individuals will have abnormal blood tests for other reasons. Similarly, many people with a positive FIT will have normal blood tests. For these reasons, 
medRxiv preprint doi: https://doi.org/10.1101/2021.10.22.21263919; this version posted October 26, 2021. The copyright holder for this preprint (which was not certified by peer review) is the author/funder, who has granted medRxiv a license to display the preprint in perpetuity.

All rights reserved. No reuse allowed without permission.

although the model fit may improve by including more variables this does not result in better discrimination for colorectal cancer above FIT alone.

\section{Strengths and Limitations}

This study has some strengths. This is the largest cohort of symptomatic primary care patients tested with FIT in the UK and as a result is highly valuable to inform future guidelines around FIT for triage of symptomatic patients. The study comprises tests prior to and during the COVID-19 pandemic and suggests that among primary care tests, the performance of FIT has remained stable throughout. Centralized FIT and blood testing at the the OUHT Clinical Biochemistry Laboratory serves primary care clinicians county-wide and allowed for highly complete assessment of FIT and blood test values. We accessed the referral text to explore the performance of FIT in strata defined by GP reported symptoms. The prevalence of and type of symptoms reported may have differed if we had accessed primary care records or asked patients to report their symptoms directly ${ }^{23}$. A 6-month followup period was used for the primary analysis to optimize the number of cancers included but in sensitivity analyses that aligned with national guideline-setting, 12-month follow-up showed similar results.

With respect to limitations, the sample was restricted to individuals for whom blood test results were available within a 90-day window surrounding FIT. As serum ferritin and CRP results were only available for a subset of those undergoing FIT, we used multiple imputation to compare models generated from stepwise selection in imputed and complete case datasets. Models included FIT as continuous, categorical, and using splines. Blood tests were included as continuous and categorical (abnormal vs. abnormal). In each permutation, different variables were retained suggesting some instability. As no predictive model was identified that performed better than FIT alone, neither internal validation nor optimism correction were pursued. Further work combining large prospective cohorts with uniform collection of common blood tests including CRP and ferritin at baseline could improve our understanding of the predictive importance of these test results.

\section{Comparison with existing literature}

A recent meta-analysis of FIT at a threshold of $10 \mu \mathrm{g} \mathrm{Hb} / \mathrm{g}$ faeces estimated a sensitivity of $87.2 \%$ and a specificity of $84.4 \%(n=48,872)^{8}$. In the current study, the sensitivity and specificity of FIT-alone were $92.1 \%$ and $91.5 \%$ respectively. The meta-analysis found that the type of reference standard used (colonoscopy or follow-up), the place of recruitment (primary care facility or colonoscopy unit) and CRC prevalence ( $\geq 3 \%$ ) were significant sources of heterogeneity in sensitivity and specificity. These factors likely explain, at least in part, the higher sensitivity and specificity observed in this study.

This is the one of two studies to formally and systematically evaluate blood tests in addition to FIT in symptomatic patients, and one of few to analyze FIT supplemented with other variables. The $\mathrm{f}-\mathrm{Hb}$, age and sex test score (FAST) was not superior to FIT alone ${ }^{12}$. COLONPREDICT included FIT, rectal bleeding, benign anorectal lesions, rectal mass, serum carcinoembryonic antigen, blood haemoglobin, colonoscopy in the last 10 years, treatment with aspirin, sex and age, and was derived and validated in a higher-risk referred population $^{24}$. The COLONPREDICT model achieved $89 \%$ sensitivity and $75.8 \%$ specificity, both lower than the performance of FIT alone in this study.

A UK-based study of whether demographic, lifestyle (e.g., smoking, physical activity), or clinical factors (family history, symptoms) could add to the predictive value of FIT found that 
only family history of polyps showed a significant association once FIT was taken into account ${ }^{25}$. In the current study, family history was not retained in stepwise models, however the indicator was based on the physicians referral notes whereas in the aforementioned study, patients were prospectively asked about family history.

Implications for research and practice

Adding blood test results to FIT does not appear to improve on the performance of FIT in primary care in a clinically meaningful way. The lack of an apparent age-effect after taking into account FIT suggests that age-specific thresholds for FIT positivity would not improve test performance. Particularly in light of the COVID pandemic and the suspected accumulation of undiagnosed cancers and unscreened adults ${ }^{11}$, effective methods to triage low and/or "intermediate" risk patients to referral are more needed than ever ${ }^{26}$. Our results suggest however, that neither age, nor blood tests, nor clinical indication as recorded by the physician should be used to inform referral to colonoscopy after FIT.

FIT alone is simple, easily implemented and effective to triage patients from primary care to colonoscopy. A key question remains how to detect FIT negative colorectal cancers ${ }^{8}$. Based on the false negatives in this study, no practical rules using blood tests or clinical indication were apparent. For example, while half the false negatives had raised CRP, scoping all patients with raised CRP regardless of FIT would increase the false positives by at least twofold. Future research may benefit from an agnostic approach to building the prediction model. For example, new predictive markers could be discovered by applying machine learning models to large, representative databases of electronic health records ${ }^{27}$.

Continued research into alternative risk stratification tools to reduce false negatives and false positives is worthwhile. For example, urinary volatile organic compounds may have promise as a second-stage/rule-out test to complement $\mathrm{FIT}^{1028}$. Other risk stratification tools that have been suggested in the screening setting such as polygenic risk scores ${ }^{29-31}$, or emerging technologies such as circulating and/or faecal tumor $\mathrm{DNA}^{32}$, could also be explored in combination with FIT for triage of primary care patients.

In the interim, follow-up care of FIT-negative patients should likely focus on safety netting, including re-evaluation of persistent and additional symptoms within a pre-specified timeframe, and potentially re-testing with FIT after a set time interval has passed, as data is lacking to support immediate repeat FIT testing at this time ${ }^{33-35}$. 


\section{TABLES}

Table 1. Characteristics of patients receiving symptomatic FIT tests by study inclusion status and outcome.

\begin{tabular}{|c|c|c|c|c|c|c|}
\hline & \multicolumn{2}{|c|}{ All FIT tests } & \multicolumn{2}{|c|}{ Included } & \multicolumn{2}{|c|}{ Cancer } \\
\hline & $\mathrm{n}$ & \multirow{2}{*}{$\frac{\%}{100}$} & \multirow{2}{*}{$\frac{n}{16,604}$} & \multirow{3}{*}{$\frac{\%}{100}$} & \multirow{2}{*}{$\frac{n}{139}$} & \multirow{3}{*}{$\%$} \\
\hline & 18,656 & & & & & \\
\hline Age & & & & & & \\
\hline $0-18$ & 95 & 1 & 0 & 0 & 0 & 0 \\
\hline 18-39.9 & 1,651 & 9 & 1,390 & 8 & 9 & 6 \\
\hline $40-49.9$ & 2,553 & 14 & 2,278 & 14 & 12 & 9 \\
\hline $50-59.9$ & 4,679 & 25 & 4,181 & 25 & 20 & 14 \\
\hline $60-69.9$ & 3,186 & 17 & 2,892 & 17 & 21 & 15 \\
\hline $70-79.9$ & 3,711 & 20 & 3,330 & 20 & 36 & 26 \\
\hline$\geq 80$ & 2,781 & 15 & 2,533 & 15 & 41 & 29 \\
\hline Median (IQR) & 61 & $(50,74)$ & 61 & $(51,75)$ & 72 & $(57,81)$ \\
\hline \multicolumn{7}{|l|}{ Sex } \\
\hline Male & 7,926 & 42 & 7,019 & 42 & 83 & 60 \\
\hline Female & 10,728 & 58 & 9,585 & 58 & 56 & 40 \\
\hline Unknown & 2 & 0 & 0 & 0 & 0 & 0 \\
\hline \multicolumn{7}{|l|}{ FIT $(\mu \mathrm{g} \mathrm{Hb} / g)$} \\
\hline $0-1.9$ & 15,298 & 82 & 13,757 & 83 & 5 & 4 \\
\hline $2-9.9$ & 1,409 & 8 & 1,318 & 8 & 6 & 4 \\
\hline $10-99.9$ & 1,072 & 6 & 1,023 & 6 & 51 & 37 \\
\hline$\geq 100$ & 539 & 3 & 506 & 3 & 77 & 55 \\
\hline Missing & 338 & 2 & 0 & 0 & & \\
\hline Median (IQR) & 0 & $(0,0.7)$ & 0.2 & $(0,0.8)$ & 135.5 & $3.4,450)$ \\
\hline \multicolumn{7}{|l|}{ Blood test results* } \\
\hline Low haemoglobin ${ }^{a}$ & 5,186 & 31 & 5,076 & 31 & 72 & 52 \\
\hline High platelets ${ }^{\mathrm{b}}$ & 556 & 3 & 546 & 3 & 13 & 9 \\
\hline High white cells ${ }^{c}$ & 832 & 5 & 820 & 5 & 9 & 6 \\
\hline Low mean cell haemoglobin ${ }^{d}$ & 2,792 & 17 & 2,730 & 16 & 47 & 34 \\
\hline Low mean cell volume $e^{\mathrm{e}}$ & 1,014 & 6 & 980 & 6 & 30 & 22 \\
\hline Any abnormal FBC & 6,521 & 35 & 6,392 & 38 & 81 & 58 \\
\hline Low serum ferritin ${ }^{f}$ & 2,015 & 22 & 1,962 & 22 & 36 & 40 \\
\hline High serum ferritin ${ }^{g}$ & 457 & 5 & 444 & 5 & 3 & 3 \\
\hline High C-reactive protein ${ }^{h}$ & 1,748 & 14 & 1,720 & 14 & 31 & 31 \\
\hline \multicolumn{7}{|l|}{ Symptoms - GP reported } \\
\hline Abdominal pain & 3,299 & 18 & 2,941 & 18 & 23 & 17 \\
\hline Blood in stool & 1,759 & 9 & 1,451 & 9 & 22 & 16 \\
\hline Melaena & 298 & 2 & 238 & 1 & 0 & 0 \\
\hline Change in bowel habit & 7,511 & 40 & 6,656 & 40 & 45 & 32 \\
\hline Diarrhoea & 2,651 & 14 & 2,315 & 14 & 13 & 9 \\
\hline Constipation & 722 & 4 & 608 & 4 & 1 & 1 \\
\hline Fatigue & 199 & 1 & 193 & 1 & 1 & 1 \\
\hline Rectal pain & 106 & 1 & 95 & 1 & 0 & 0 \\
\hline Bloating & 594 & 3 & 541 & 3 & 2 & 1 \\
\hline Family history of cancer & 342 & 2 & 263 & 2 & 2 & 1 \\
\hline Weight loss & 1,448 & 8 & 1,348 & 8 & 9 & 6 \\
\hline \multicolumn{7}{|l|}{ Blood - GP reported } \\
\hline Anaemia (any) & 4,517 & 24 & 4,272 & 26 & 48 & 35 \\
\hline Iron deficiency anaemia & 1,926 & 10 & 1,793 & 11 & 18 & 13 \\
\hline Thrombocytosis & 216 & 1 & 204 & 1 & 2 & 1 \\
\hline
\end{tabular}

IQR: Interquartile range. "percent with non-missing values ${ }^{a}<130 \mathrm{~g} / \mathrm{L}$ in $\mathrm{men}$ and $<120 \mathrm{~g} / \mathrm{L}$ in women; ${ }^{\text {b }}>400 \mu \mathrm{L} / \mathrm{L} ;{ }^{\mathrm{c}}<11,000 / \mathrm{mL} ;{ }^{\mathrm{d}}<27.4 \mathrm{pg} / \mathrm{cell} ;{ }^{\mathrm{e}}<80 \mathrm{fL} ;{ }^{\mathrm{f}}<20 \mathrm{ng} / \mathrm{mL} ;{ }^{\mathrm{g}} \geq 350 \mathrm{ng} / \mathrm{mL} ;{ }^{\mathrm{h}}>10$ Any abnormal full blood count (FBC) refers to any abnormal result of heamoglobin, platelets, white cells, mean cell haemoglobin and mean cell volume.

Note: Serum ferritin and c-reactive protein tests were only conducted for a subset of patients ( $\mathrm{n}=8,922$ and 12,201 respectively) 
Table 2. Test performance as measured by positive and negative predictive value (PPV, NPV), sensitivity, specificity, positive FITs per cancer detected and cancer miss rate per 10,000 negative tests. FIT alone and threshold-based approach to FIT-blood test pairs.

\begin{tabular}{|c|c|c|c|c|c|c|c|}
\hline & Test criteria & PPV $(95 \% \mathrm{Cl})$ & NPV $(95 \% \mathrm{Cl})$ & Sensitivity $(95 \% \mathrm{Cl})$ & Specificity $(95 \% \mathrm{Cl})$ & $\begin{array}{c}\text { Positive FITs } \\
\text { to detect one } \\
\text { cancer }\end{array}$ & $\begin{array}{c}\text { Cancer miss } \\
\text { rate per } 10,000 \\
\text { negative tests }\end{array}$ \\
\hline \multicolumn{8}{|c|}{$\begin{array}{l}\text { FIT alone } \\
\end{array}$} \\
\hline & $F I T \geq 2 \mu g ~ H b / g$ & $4.7 \%(4,5.5)$ & $100.0 \%(99.9,100)$ & $96.4 \%(91.9,98.5)$ & $83.5 \%(82.9,84.1)$ & 21 & 4 \\
\hline & $\mathrm{FIT} \geq 10 \mu \mathrm{g} \mathrm{Hb} / \mathrm{g}$ & $8.4 \%(7.1,9.9)$ & $99.9 \%(99.9,100)$ & $92.1 \%(86.4,95.5)$ & $91.5 \%(91.1,91.9)$ & 12 & 7 \\
\hline \multicolumn{8}{|c|}{ FIT-Blood Test Pairs } \\
\hline \multirow{9}{*}{$\begin{array}{c}F I T \geq 2 \mu g \\
H b / g \text { AND }\end{array}$} & Low haemoglobin ${ }^{\mathrm{a}}$ & $5.1 \%(4.3,6.2)$ & $99.9 \%(99.8,99.9)$ & $89 \%(82.2,93.5)$ & $83.4 \%(82.7,84)$ & 17 & 44 \\
\hline & High platelets ${ }^{\mathrm{b}}$ & $5.8 \%(4.6,7.3)$ & $99.6 \%(99.4,99.7)$ & $51 \%(42.9,59.2)$ & $93.0 \%(92.6,93.4)$ & 11 & 77 \\
\hline & High white cells ${ }^{c}$ & $8.7 \%(5.2,14.4)$ & $92.8 \%(91.5,93.9)$ & $9.4 \%(5.5,15.3)$ & $92.3 \%(91,93.4)$ & 29 & 80 \\
\hline & Low mean cell haemoglobin ${ }^{d}$ & $3.4 \%(1.7,6.6)$ & $99.2 \%(99.1,99.3)$ & $5.8 \%(2.9,10.9)$ & $98.6 \%(98.4,98.8)$ & 12 & 57 \\
\hline & Low mean cell volume $e^{e}$ & $8.0 \%(6.1,10.5)$ & $99.4 \%(99.3,99.5)$ & $33.8 \%(26.5,42)$ & $96.7 \%(96.4,97)$ & 6 & 66 \\
\hline & Any abnormal FBC & $15.9 \%(11.4,21.8)$ & $99.3 \%(99.2,99.4)$ & $21.6 \%(15.6,29.1)$ & $99.0 \%(98.9,99.2)$ & 19 & 40 \\
\hline & Low serum ferritin ${ }^{\dagger}$ & $5.4 \%(4.3,6.7)$ & $99.6 \%(99.5,99.7)$ & $56.8 \%(48.5,64.8)$ & $91.6 \%(91.1,92)$ & 10 & 63 \\
\hline & High serum ferriting & $10.0 \%(7.3,13.6)$ & $99.4 \%(99.2,99.5)$ & $40.0 \%(30.5,50.3)$ & $96.3 \%(95.9,96.7)$ & 33 & 99 \\
\hline & High C-reactive protein ${ }^{\mathrm{h}}$ & $3.0 \%(1,8.5)$ & $99.0 \%(98.8,99.2)$ & $3.3 \%(1.1,9.3)$ & $98.9 \%(98.7,99.1)$ & 18 & 59 \\
\hline \multirow{9}{*}{$\begin{array}{l}F I T \geq 10 \mu g \\
H b / g \text { AND }\end{array}$} & Low haemoglobin ${ }^{\mathrm{a}}$ & $5.6 \%(4,7.8)$ & $99.4 \%(99.3,99.5)$ & $31.0 \%(22.8,40.6)$ & $95.7 \%(95.3,96)$ & 10 & 44 \\
\hline & High platelets ${ }^{\mathrm{b}}$ & $10.3 \%(8.2,12.8)$ & $99.6 \%(99.4,99.7)$ & $49.6 \%(41.5,57.8)$ & $96.4 \%(96.1,96.6)$ & 8 & 77 \\
\hline & High white cells ${ }^{c}$ & $12.2 \%(7.1,20.2)$ & $99.2 \%(99.1,99.4)$ & $8.6 \%(5,14.5)$ & $99.5 \%(99.4,99.6)$ & 17 & 80 \\
\hline & Low mean cell haemoglobin ${ }^{d}$ & $5.8 \%(2.9,10.9)$ & $99.2 \%(99.1,99.3)$ & $5.8 \%(2.9,10.9)$ & $99.2 \%(99.1,99.3)$ & 7 & 58 \\
\hline & Low mean cell volume $\mathrm{e}^{\mathrm{e}}$ & $13.5 \%(10.3,17.6)$ & $99.4 \%(99.3,99.5)$ & $32.4 \%(25.2,40.5)$ & $98.3 \%(98,98.4)$ & 4 & 67 \\
\hline & Any abnormal FBC & $23.3 \%(16.7,31.7)$ & $99.3 \%(99.2,99.4)$ & $20.1 \%(14.3,27.6)$ & $99.4 \%(99.3,99.5)$ & 10 & 39 \\
\hline & Low serum ferritin ${ }^{\dagger}$ & $9.6 \%(7.7,11.8)$ & $99.6 \%(99.5,99.7)$ & $55.4 \%(47.1,63.4)$ & $95.6 \%(95.3,95.9)$ & 6 & 62 \\
\hline & High serum ferritin ${ }^{g}$ & $17.0 \%(12.5,22.6)$ & $99.4 \%(99.2,99.5)$ & $40.0 \%(30.5,50.3)$ & $98.0 \%(97.7,98.3)$ & 15 & 98 \\
\hline & High C-reactive protein $^{\mathrm{h}}$ & $6.5 \%(2.2,17.5)$ & $99.0 \%(98.8,99.2)$ & $3.3 \%(1.1,9.3)$ & $99.5 \%(99.3,99.6)$ & 13 & 62 \\
\hline
\end{tabular}

${ }_{\mathrm{a}}<130 \mathrm{~g} / \mathrm{L}$ in men and $<120 \mathrm{~g} / \mathrm{L}$ in women; ${ }^{\mathrm{b}}>400 \mu \mathrm{LL} / \mathrm{L} ;{ }^{\mathrm{c}}<11,000 / \mathrm{mL} ;{ }^{\mathrm{d}}<27.4 \mathrm{pg} / \mathrm{cell} ;{ }^{\mathrm{e}}<80 \mathrm{fL} ;{ }^{f}<20 \mathrm{ng} / \mathrm{mL} ;{ }^{\mathrm{g}} \geq 350 \mathrm{ng} / \mathrm{mL} ;{ }^{\mathrm{h}}>10 \mathrm{mg} / \mathrm{L}$. Cl: Confidence interval.

Note: Serum ferritin and c-reactive protein tests were only conducted for a subset of patients ( $n=8,923$ and 12,202 respectively) 
Table 3. Test performance as measured by positive and negative predictive value (PPV, NPV), sensitivity, specificity, positive FITs per cancer detected and cancer miss rate per 10,000 negative tests. FIT alone and model-based approach.

\begin{tabular}{|c|c|c|c|c|c|c|}
\hline Test criteria & PPV $(95 \%$ Cl) & NPV $(95 \% \mathrm{Cl})$ & Sensitivity $(95 \% \mathrm{Cl})$ & Specificity (95\% Cl) & $\begin{array}{l}\text { Positive } \\
\text { FITs to } \\
\text { detect one } \\
\text { cancer }\end{array}$ & $\begin{array}{l}\text { Cancer miss } \\
\text { rate per } \\
10,000 \\
\text { negative tests } \\
\end{array}$ \\
\hline \multicolumn{7}{|c|}{ FIT alone } \\
\hline $\begin{aligned} & \mathrm{FIT} \geq 10 \mu \mathrm{g} \mathrm{Hb} / \mathrm{g} \\
& \text { In subset with serum } \\
& \mathrm{FIT} \geq 10 \mu \mathrm{g} \mathrm{Hb} / \mathrm{g} \quad \text { ferritin \& C-reactive }\end{aligned}$ & $8.4 \%(7.1,9.9)$ & $99.9 \%(99.9,100)$ & $92.1 \%(86.4,95.5)$ & $91.5 \%(91.1,91.9)$ & 12 & 7 \\
\hline protein $^{\mathrm{a}}$ & $8.8 \%(6.9,11.1)$ & $99.9 \%(99.8,100)$ & $93.8 \%(85,97.5)$ & $90.0 \%(89.2,90.7)$ & 11 & 7 \\
\hline \multicolumn{7}{|c|}{ Multivariable model including FIT } \\
\hline 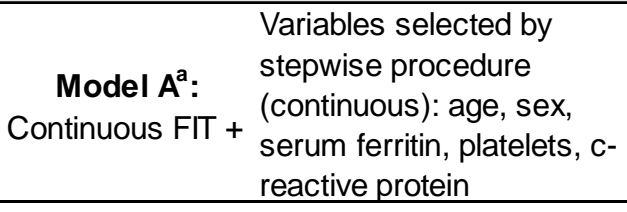 & $1.7 \%(1.4,2.2)$ & $99.9 \%(99.6,99.9)$ & $93.8 \%(85,97.5)$ & $45.9 \%(44.7,47.1)$ & 57 & 14 \\
\hline $\begin{array}{cl}\text { Model B: } & \begin{array}{l}\text { Variables selected by } \\
\text { stepwise procedure }\end{array} \\
\mathrm{FIT} \geq 10 \mu \mathrm{g} \mathrm{Hb} / \mathrm{g}+ & \begin{array}{l}\text { (categorical): Sex, low } \\
\text { mean cell volume }\end{array}\end{array}$ & $7.4 \%(6.2,8.7)$ & $99.9 \%(99.9,100)$ & $93.5 \%(88.2,96.6)$ & $90.1 \%(89.6,90.5)$ & 14 & 6 \\
\hline $\begin{array}{cl}\text { Model C: } & \begin{array}{l}\text { Variables selected by } \\
\text { stepwise procedure }\end{array} \\
\text { FIT Spline }+ & \begin{array}{l}\text { (categorical): Sex, low } \\
\text { mean cell volume }\end{array} \\
\end{array}$ & $8.4 \%(7.1,9.9)$ & $99.9 \%(99.9,100)$ & $92.1 \%(86.4,95.5)$ & $91.5 \%(91.1,91.9)$ & 12 & 7 \\
\hline
\end{tabular}

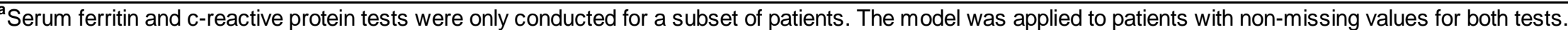

In the model-based approach, a fixed threshold for a positive test was set to achieve the sensitivity of a FIT threshold of 10 in the FIT alone approach.

$\mathrm{Cl}$ : Confidence interval 
Table 4. Clinical characteristics of patients who had a false-negative FIT at a threshold of $10 \mu \mathrm{g} \mathrm{Hb} / \mathrm{g}$ faeces.

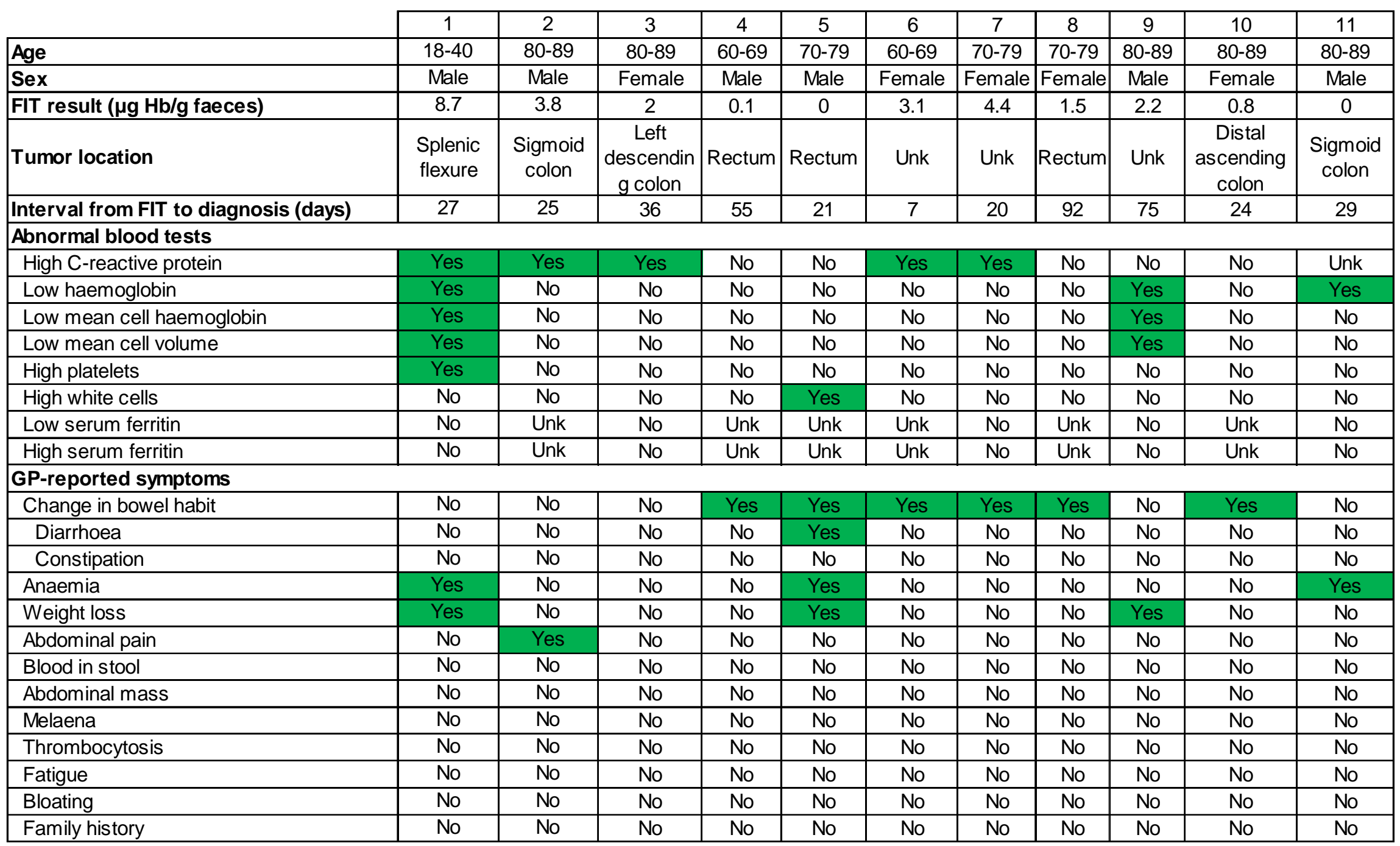

Note: Serum ferritin and c-reactive protein were only assessed in a subset of patients. Unk: Unknown. 
medRxiv preprint doi: https://doi.org/10.1101/2021.10.22.21263919; this version posted October 26, 2021. The copyright holder for this preprint (which was not certified by peer review) is the author/funder, who has granted medRxiv a license to display the preprint in perpetuity.

All rights reserved. No reuse allowed without permission.

\section{FIGURES}

\begin{tabular}{|} 
All consecutive FITs* requested by GPs and \\
analyzed by OUHT between January $4^{\text {th }} 2017$ to \\
December $21^{\text {st }} 2020$ \\
$\mathrm{~N}=18,656$
\end{tabular}

$\longrightarrow \begin{gathered}\text { Missing blood test values } \\ \mathrm{n}=1,786(9.6 \%)\end{gathered}$
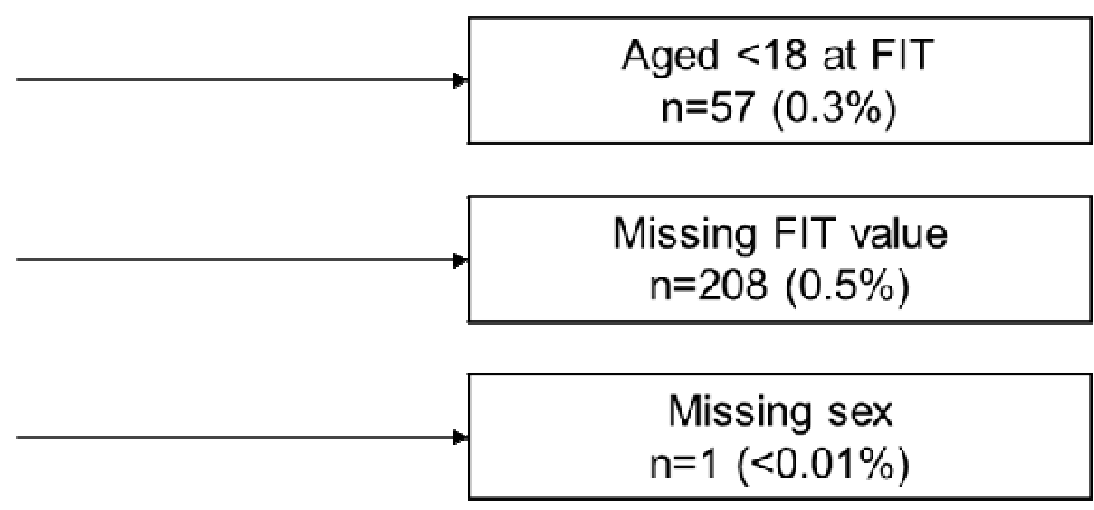

Included FITs/patients

$n=16,604(89.0 \%)$

Figure 1. Selection criteria for inclusion. *First FITs per individual. 


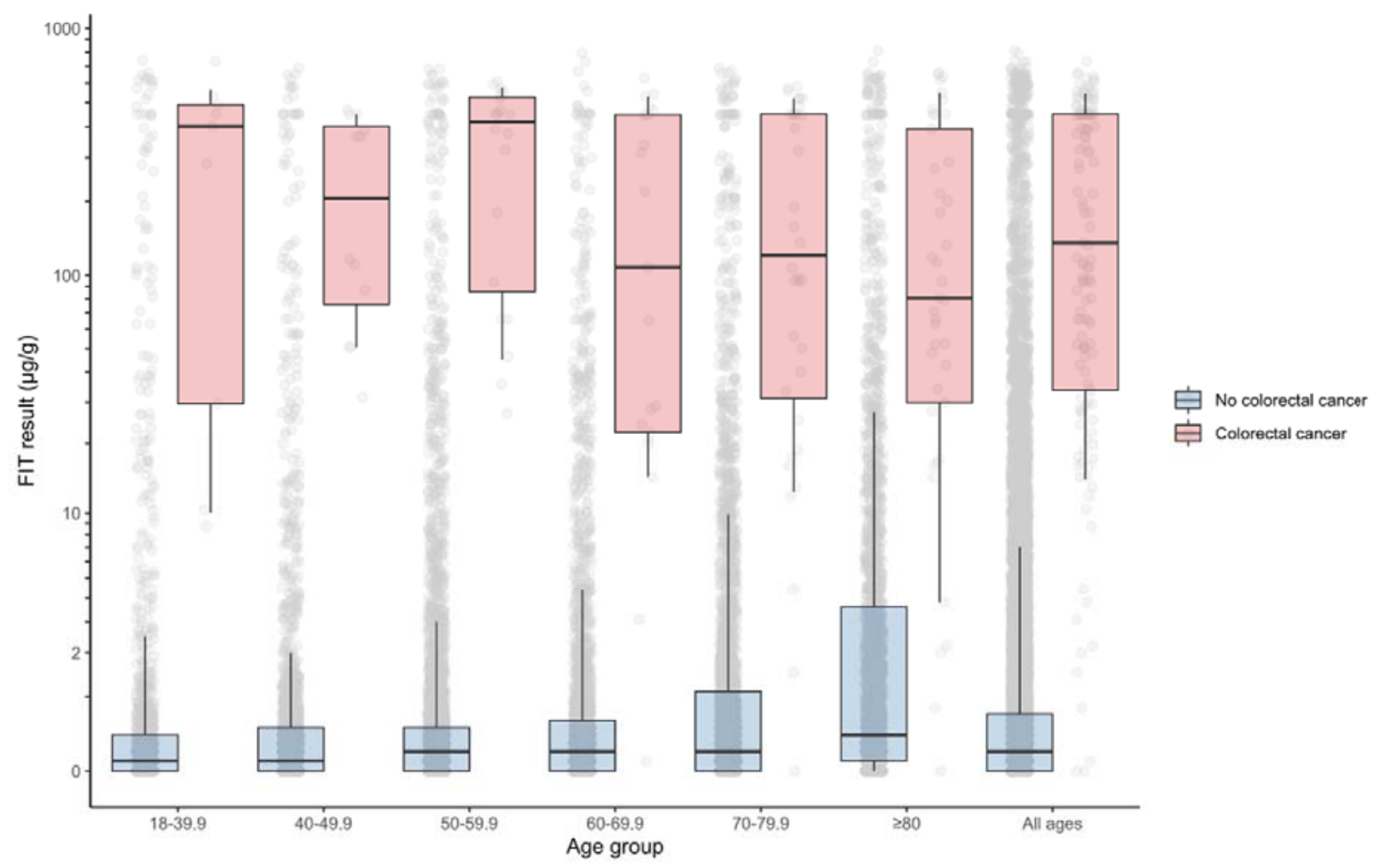

Figure 2. Distribution of FIT score by age and outcome. Boxes indicate median and interquartile range. Whiskers indicate 10th and 90th percentiles. The shape of the distribution corresponds to $\log 10(\mathrm{FIT}+1)$ whereas tick marks are drawn at actual FIT values. 

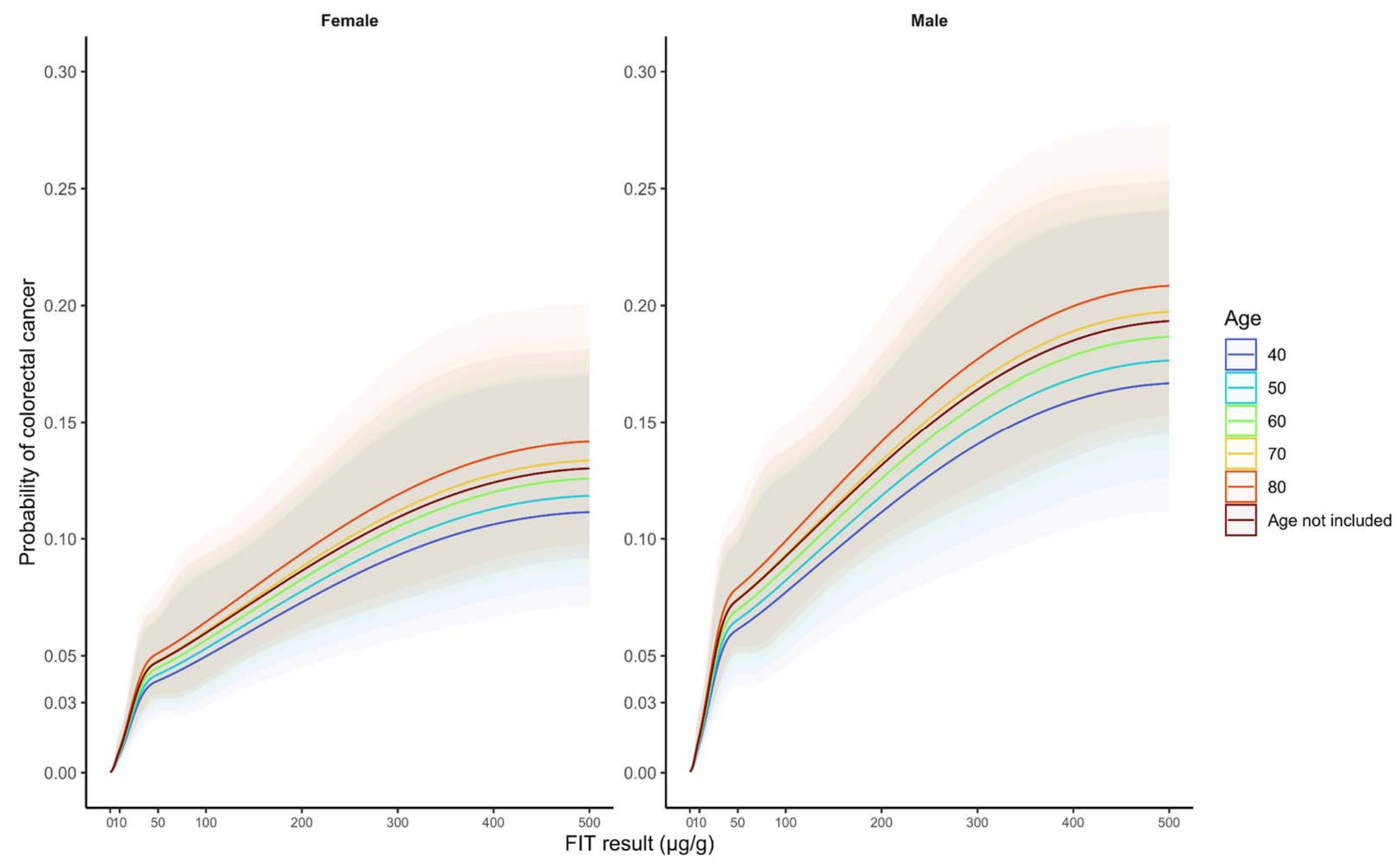

Figure 3. Probability of colorectal cancer by sex, age, and FIT score with $95 \%$ confidence intervals indicated with shading (See Model C). The restricted cubic spline function was specified to have knots at FIT values of 2, 10, 50 and 100. 


\section{REFERENCES}

1. Thompson $M, O^{\prime}$ Leary $D$, Heath $\mathrm{I}$, et al. Have large increases in fast track referrals improved bowel cancer outcomes in UK? bmj 2020;371

2. NICE. Quantitative faecal immunochemical tests to guide referral for colorectal cancer in primary care [DG30], 2017.

3. Westwood M, Ramos IC, Lang S, et al. Faecal immunochemical tests to triage patients with lower abdominal symptoms for suspected colorectal cancer referrals in primary care: a systematic review and cost-effectiveness analysis. Health Technology Assessment (Winchester, England) 2017;21(33):1.

4. Mowat C, Digby J, Strachan JA, et al. Faecal haemoglobin and faecal calprotectin as indicators of bowel disease in patients presenting to primary care with bowel symptoms. Gut 2016;65(9):1463-69.

5. Nicholson BD, James T, East JE, et al. Experience of adopting faecal immunochemical testing to meet the NICE colorectal cancer referral criteria for low-risk symptomatic primary care patients in Oxfordshire, UK. Frontline Gastroenterology 2019;10(4):347-55.

6. van Melle M, Yep Manzano SIS, Wilson $\mathrm{H}$, et al. Faecal immunochemical test to triage patients with abdominal symptoms for suspected colorectal cancer in primary care: review of international use and guidelines. Fam Pract 2020;37(5):606-15. doi:

10.1093/fampra/cmaa043 [published Online First: 2020/05/08]

7. Bailey SER, Abel GA, Atkins A, et al. Diagnostic performance of a faecal immunochemical test for patients with low-risk symptoms of colorectal cancer in primary care: an evaluation in the South West of England. Br J Cancer 2021;124(7):1231-36. doi: 10.1038/s41416-020-01221-9 [published Online First: 2021/01/20]

8. Pin-Vieito N, Tejido-Sandoval C, de Vicente-Bielza N, et al. Faecal immunochemical tests safely enhance rational use of resources during the assessment of suspected symptomatic colorectal cancer in primary care: systematic review and meta-analysis. Gut 2021

9. D'Souza N, Georgiou Delisle T, Chen M, et al. Faecal immunochemical test is superior to symptoms in predicting pathology in patients with suspected colorectal cancer sym ptoms referred on a 2WW pathway: a diagnostic accuracy study. Gut 2020 doi: 10.1136/gutjnl-2020-321956 [published Online First: 2020/10/23]

10. Chandrapalan S, Bosch S, Cubiella J, et al. Systematic review with meta-analysis: volatile organic compound analysis to improve faecal immunochemical testing in the detection of colorectal cancer. Aliment Pharmacol Ther 2021;54(1):14-23. doi: 10.1111/apt.16405 [published Online First: 2021/05/19]

11. Morris EJA, Goldacre R, Spata E, et al. Impact of the COVID-19 pandemic on the detection and management of colorectal cancer in England: a population-based study. The Lancet Gastroenterology \& Hepatology 2021 doi: 10.1016/s2468-1253(21)00005-4

12. Digby J, Strachan JA, Mowat C, et al. Appraisal of the faecal haemoglobin, age and sex test (FAST) score in assessment of patients with lower bowel symptoms: an observational study. BMC gastroenterology 2019;19(1):1-7.

13. Bailey J, Ibrahim H, Bunce J, et al. Quantitative FIT stratification is superior to NICE referral criteria NG12 in a high-risk colorectal cancer population. Techniques in Coloproctology 2021:1-4.

14. National Health Service. Clinical guide for triaging patients with lower gastrointestinal symptoms, 2020.

15. Bailey JA, Weller J, Chapman CJ, et al. Faecal immunochemical testing and blood tests for prioritization of urgent colorectal cancer referrals in symptomatic patients: a 2-year evaluation. BJS Open 2021;5(2) doi: 10.1093/bjsopen/zraa056 [published Online First: 2021/03/12] 
medRxiv preprint doi: https://doi.org/10.1101/2021.10.22.21263919; this version posted October 26, 2021. The copyright holder for this preprint (which was not certified by peer review) is the author/funder, who has granted medRxiv a license to display the preprint in perpetuity.

All rights reserved. No reuse allowed without permission.

16. Nicholson BD, James $\mathrm{T}$, Paddon $\mathrm{M}$, et al. Faecal immunochemical testing for adults with symptoms of colorectal cancer attending English primary care: a retrospective cohort study of 14487 consecutive test requests. Aliment Pharmacol Ther 2020;52(6):1031-41. doi: 10.1111/apt.15969

17. James T, Nicholson B, Marr R, et al. Faecal immunochemical testing (FIT): sources of result variation based on three years of routine testing of symptomatic patients in English primary care. British Journal of Biomedical Science 2021:1-7.

18. Virdee PS, Marian IR, Mansouri A, et al. The full blood count blood test for colorectal cancer detection: a systematic review, meta-analysis, and critical appraisal. Cancers 2020;12(9):2348.

19. Wilkinson I, Wilkinson IB, Raine T, et al. Oxford handbook of clinical medicine: Oxford University Press 2017.

20. Austin PC, Steyerberg EW. Events per variable (EPV) and the relative performance of different strategies for estimating the out-of-sample validity of logistic regression models. Statistical methods in medical research 2017;26(2):796-808.

21. Newcombe RG. Two-sided confidence intervals for the single proportion: comparison of seven methods. Statistics in medicine 1998;17(8):857-72.

22. NICE. Suspected cancer: recognition and referral [NG12] 2015.

23. Hogberg C, Karling P, Rutegard J, et al. Patient-reported and doctor-reported symptoms when faecal immunochemical tests are requested in primary care in the diagnosis of colorectal cancer and inflammatory bowel disease: a prospective study. BMC Fam Pract 2020;21(1):129. doi: 10.1186/s12875-020-01194-x [published Online First: 2020/07/03]

24. Cubiella J, Vega P, Salve M, et al. Development and external validation of a faecal immunochemical test-based prediction model for colorectal cancer detection in symptomatic patients. BMC medicine 2016;14(1):128.

25. Digby J, Steele RJ, Strachan JA, et al. Do other variables add value to assessment of the risk of colorectal disease using faecal immunochemical tests for haemoglobin? Ann Clin Biochem 2019;56(4):472-79. doi: 10.1177/0004563219839423 [published Online First: 2019/05/01]

26. Arasaradnam RP, Bhala N, Evans C, et al. Faecal immunochemical testing in the COVID-19 era: balancing risk and costs. The Lancet Gastroenterology \& Hepatology 2020;5(8):717-19.

27. Goldstein BA, Navar AM, Pencina MJ, et al. Opportunities and challenges in developing risk prediction models with electronic health records data: a systematic review. Journal of the American Medical Informatics Association 2017;24(1):198-208.

28. Widlak MM, Neal M, Daulton E, et al. Risk stratification of symptomatic patients suspected of colorectal cancer using faecal and urinary markers. Colorectal Disease 2018;20(12):0335042.

29. Frampton M, Law $P$, Litchfield K, et al. Implications of polygenic risk for personalised colorectal cancer screening. Annals of Oncology 2016;27(3):429-34.

30. Hull MA, Rees CJ, Sharp L, et al. A risk-stratified approach to colorectal cancer prevention and diagnosis. Nature Reviews Gastroenterology \& Hepatology 2020;17(12):773-80.

31. Melson JE, Imperiale TF, Itzkowitz SH, et al. AGA white paper: roadmap for the future of colorectal cancer screening in the United States. Clinical Gastroenterology and Hepatology 2020;18(12):2667-78. e2.

32. Bach S, Sluiter NR, Beagan JJ, et al. Circulating tumor DNA analysis: clinical implications for colorectal cancer patients. A systematic review. JNCl cancer spectrum 2019;3(3):pkz042.

33. Cubiella J, Marzo-Castillejo M, Mascort-Roca JJ, et al. Clinical practice guideline. Diagnosis and prevention of colorectal cancer. 2018 Update. Gastroenterología y Hepatología (English Edition) 2018;41(9):585-96.

34. Turvill J, Mellen S, Jeffery L, et al. Diagnostic accuracy of one or two faecal haemoglobin and calprotectin measurements in patients with suspected colorectal cancer. Scandinavian journal of gastroenterology 2018;53(12):1526-34. 
medRxiv preprint doi: https://doi.org/10.1101/2021.10.22.21263919; this version posted October 26, 2021. The copyright holder for this preprint (which was not certified by peer review) is the author/funder, who has granted medRxiv a license to display the preprint in perpetuity.

All rights reserved. No reuse allowed without permission.

35. Nicholson BD, Mant D, Bankhead C. Can safety-netting improve cancer detection in patients with vague symptoms? BMJ 2016;355 